\title{
Attitudes of General Practitioners and Pediatricians to Management of Acute Pyelonephritis in Children
}

\author{
A. Al-Eisa a $\quad$ M. Al-Mosawi ${ }^{\text {b }}$ R. Gupta ${ }^{\text {c }}$ T.M. D'Souza ${ }^{d}$ P.N. Sharma ${ }^{\text {e }}$ \\ aDepartment of Pediatrics, Faculty of Medicine, Kuwait University, bPrimary Health Care, \\ Ministry of Health, Kuwait, and Departments of ${ }^{\mathrm{C}}$ Radiology, ${ }^{\mathrm{d} P e d i a t r i c s}$ and \\ ${ }^{e}$ Computer Sciences, Faculty of Medicine, Kuwait University, Kuwait
}

\section{Key Words}

Attitudes · Survey - Acute pyelonephritis .

Antibiotics $\cdot$ Renal scarring

\begin{abstract}
Objective: To study the attitudes of different groups of physicians toward management of acute pyelonephritis in children and the impact of such attitudes on the long-term sequelae of this problem. Materials and Methods: A questionnaire, describing a case history of a child with acute pyelonephritis, was distributed to general practitioners working in 12 primary health care centers and pediatricians working in the pediatric departments of the 6 main hospitals in Kuwait. The responses of the two groups were analyzed regarding their views toward hospitalization of the child, investigations requested, the choice of antibiotics, its route of administration, duration of treatment and the need for long-term follow-up. Results: A total of 83 general practitioners (group A) and 65 hospi-
\end{abstract}

\begin{tabular}{ll}
\hline KARGER & ( 2000 S. Karger AG, Basel \\
Fax +4161306 1234 $34-7571 / 00 / 0092-0119 \$ 17.50 / 0$ \\
$\begin{array}{l}\text { E-Mail karger@karger.ch } \\
\text { www.karger.com }\end{array}$ & $\begin{array}{l}\text { Accessible online at: } \\
\text { www.karger.com/journals/mpp }\end{array}$
\end{tabular}

tal pediatricians (group B) responded to the questionnaire. Hospitalization of the child was thought to be essential by $19 \%$ of group A compared to $89 \%$ of group B ( $p<$ $0.0001)$. Only $25 \%$ of group A decided to fully investigate the child compared to $58 \%$ of group $B(p<0.0001)$. Treatment with a single antibiotic was preferred by $72 \%$ of group $A$ compared to $80 \%$ of group B. Only $6 \%$ of group A, compared to $74 \%$ of group B favored parenteral antibiotics $(p<0.0001)$. A 7day course of treatment was considered by $70 \%$ of group $A$ and $52 \%$ of group $B$ ( $p<$ 0.02). Long-term follow-up was thought to be necessary by $63 \%$ of group A and $75 \%$ of group B. Conclusion: A marked discrepancy existed in the management of acute pyelonephritis between the two groups, indicating the need of a unified policy. Children presenting with such a problem can be managed by general practitioners on an outpatient basis provided that proper antibiotics are used, compliance is ensured and appropriate investigations and follow-up are provided.

Copyright $@ 2000$ S. Karger AG, Basel

Dr. Amal Al-Eisa, Assistant Professor

Pediatric Department, Faculty of Medicine, Kuwait University

PO Box 24923, 13110 Safat (Kuwait)

Tel. +965 5319486, Fax +965 5338940

E-MailAmal@hsc.kuniv.edu.kw 


\section{Introduction}

Urinary tract infection is a common pediatric problem in children, occurring in approximately $3 \%$ of girls and $1 \%$ of boys in the first 10 years of life [1]. Infection of the renal parenchyma can lead to serious long-term sequelae such as renal scarring, hypertension and chronic renal failure. The diagnosis of acute pyelonephritis traditionally has been made on the basis of the classic signs and symptoms of fever, flank pain or tenderness associated with pyuria and positive urine culture. However, accurate diagnosis based solely on these parameters is often difficult particularly in children less than 5 years of age [2]. Underdiagnosis of urinary tract infections in children is a common and universal problem in medical practice, both in developing as well as developed countries [3-6]. We tried, by conducting this survey, to explore the extent of such a problem in Kuwait, presented by attitudes of general practitioners compared to hospital-based pediatricians towards the management of urinary tract infections in children.

\section{Patients and Methods}

A questionnaire, having a brief case history of a child with acute pyelonephritis, was prepared. The case history was as follows: A 3-year-old girl presented with a 1-day history of fever of $39^{\circ} \mathrm{C}$ accompanied by vomiting and abdominal pain. Her urine was smelly and cloudy. A dipstick test of her urine was positive for leukocytes and nitrite. This was the first time she developed such symptoms.

The case history was followed by questions directed to the attending physician which included: treating the child in the hospital or as an outpatient, the investigations to be requested, the antibiotics to be used, its route of administration and duration, and whether follow-up after treating the infection was required for this child. The questionnaire also solicited information on the physician's current position and the length of his experience. The questionnaire was distributed to gen- eral practitioners working in 12 primary health care centers, two from each health district including: the capital, Jahra, Sabah, Hawalli, Farwaniya and Ahmadi. The same questionnaire was distributed to pediatricians working in the six main hospitals draining patients of the same previous health districts, i.e. AlAmiri, Mubarak Al-Kabeer, Sabah, Jahra, Adan and Farwaniya hospitals. Only assistant registrars and registrars were included. Senior registrars and consultants of these hospitals were not included in the study because of their longer experience in comparison to primary health care physicians. The questionnaire was collected in person from all participants of both groups. Data management and statistical analysis was performed using SSPS 9.0 on PC. The proportions of responses in the two study groups were compared using $\mathrm{z}$ test for proportions. The differences were considered statistically significant at a $\mathrm{p}$ value $<0.05$.

\section{Results}

A total of 148 physicians responded to the questionnaire. The responders were 83 general practitioners from primary health care centers (group A) and 65 hospital-based pediatricians (group B). The response rate for group A was $85 \%$ compared to $89 \%$ for group B. The clinical experience of physicians in both groups was comparable in terms of years of experience (mean 5.6 years for group A and 6.2 years for group B). From group A, 19\% preferred referring the child with acute pyelonephritis to the hospital for treatment as inpatient, while a large majority (81\%) preferred treating the child as an outpatient. From group B, $89 \%$ showed preference for treating the child in the hospital, while only $11 \%$ preferred outpatient treatment (table 1). The difference in responses between the two groups was highly significant $(p<0.0001)$. As regards investigations $40 \%$ of group A, compared to $8 \%$ of group B, felt that the child would need only urinalysis and culture $(\mathrm{p}<0.0001)$, whereas $25 \%$ of the first group thought the child would need full investigations including radiological imaging as compared to $58 \%$ of 
Table 1. Treatment modes of acute pyelonephritis for general practitioners $(\mathrm{n}=83)$ and hospital pediatricians $(n=65)$

\begin{tabular}{|c|c|c|c|c|}
\hline \multirow[t]{2}{*}{ Treatment mode } & \multicolumn{2}{|c|}{$\begin{array}{l}\text { General } \\
\text { practitioners }\end{array}$} & \multicolumn{2}{|c|}{$\begin{array}{l}\text { Hospital } \\
\text { pediatricians }\end{array}$} \\
\hline & $\mathrm{n}$ & $\%$ & $\mathrm{n}$ & $\%$ \\
\hline \multicolumn{5}{|l|}{ Treatment* } \\
\hline Inpatient & 16 & 19 & 58 & 89 \\
\hline Outpatient & 67 & 81 & 7 & 11 \\
\hline \multicolumn{5}{|l|}{ Investigations } \\
\hline Urine only* & 33 & 40 & 5 & 8 \\
\hline Urine + blood & 29 & 35 & 22 & 34 \\
\hline Urine + blood + radiology* & 21 & 25 & 38 & 58 \\
\hline \multicolumn{5}{|l|}{ Drug prescribed } \\
\hline Single antibiotic & 60 & 72 & 52 & 80 \\
\hline Two antibiotics & 10 & 12 & 6 & 9 \\
\hline Three antibiotics & 2 & 2 & 1 & 2 \\
\hline No antibiotic & 11 & 13 & 6 & 9 \\
\hline \multicolumn{5}{|l|}{ Route of administration } \\
\hline Oral* & 55 & 66 & 2 & 3 \\
\hline Parenteral* & 5 & 6 & 48 & 74 \\
\hline No preference & 23 & 28 & 15 & 23 \\
\hline \multicolumn{5}{|l|}{ Duration of treatment } \\
\hline$<5$ days & - & & 2 & 3 \\
\hline 5-7 days & 25 & 30 & 28 & 43 \\
\hline$>7$ days $* *$ & 58 & 70 & 34 & 52 \\
\hline \multicolumn{5}{|l|}{ Follow-up } \\
\hline Yes & 52 & 63 & 49 & 75 \\
\hline No & 31 & 37 & 16 & 25 \\
\hline
\end{tabular}

the hospital-based pediatricians $(\mathrm{p}<0.0001)$. Investigating the child with urine and blood tests only was favored by $35 \%$ of group A and $34 \%$ of group B. A large majority in both groups, $72 \%$ of group A and $80 \%$ of group B, preferred to treat the child using a single antibiotic. Only $12 \%$ of group A and $9 \%$ of group B respondents favored two antibiotics, with a small minority, $2 \%$ of group A and $1 \%$ group $\mathrm{B}$, opting for three antibiotics. In addition, $13 \%$ of group A and $9 \%$ of group B physicians preferred waiting for urine culture results before giving any antibiotic. Further
$66 \%$ of the general practitioners preferred to treat the child with oral antibiotics compared to $3 \%$ of the hospital pediatricians ( $p<$ 0.0001 ). On the other hand, only $6 \%$ of the general practitioners preferred the parenteral route as compared to $74 \%$ of hospital pediatricians $(p<0.0001)$. Trimethoprim-sulfamethoxazole was chosen by $45 \%$ of the general practitioners as a first line treatment as compared to only $3 \%$ of the hospital pediatricians who indicated the same choice $(\mathrm{p}<0.0001)$. On the other hand, third-generation cephalosporins were the first line of treatment for 
Table 2. Antibiotics prescribed by general practitioners $(n=83)$ and hospital pediatricians $(n=65)$

\begin{tabular}{|c|c|c|c|c|}
\hline \multirow[t]{2}{*}{ Antibiotic } & \multicolumn{2}{|c|}{$\begin{array}{l}\text { General } \\
\text { practitioners }\end{array}$} & \multicolumn{2}{|c|}{$\begin{array}{l}\text { Hospital } \\
\text { pediatricians }\end{array}$} \\
\hline & $\mathrm{n}$ & $\%$ & $\mathrm{n}$ & $\%$ \\
\hline Trimethoprim-sulfamethoxazole & $37 *$ & 45 & 2 & 3 \\
\hline Penicillins & $25^{*}$ & 30 & 3 & 5 \\
\hline Third-generation cephalosporin & $3^{*}$ & 4 & 44 & 68 \\
\hline Nitrofurantoin & 7 & 8 & 1 & 2 \\
\hline Amoxicillin + clavulanic acid & 2 & 2 & 0 & \\
\hline Aminoglycoside & 7 & 8 & 10 & 15 \\
\hline First-generation cephalosporin & 1 & 1 & 0 & \\
\hline
\end{tabular}

$68 \%$ of hospital pediatricians as compared to only $3 \%$ of the general practitioners $(p<$ 0.0001 ). The various choices of antibiotics are summarized for the two groups in table 2 . The majority of general practitioners $(70 \%)$, in comparison to $52 \%$ of hospital pediatricians, preferred to treat for more than 7 days $(\mathrm{p}<$ 0.02 ). Moreover, $63 \%$ of group A and $75 \%$ of group B thought that the child would need follow-up after treating the acute infection.

\section{Discussion}

Urinary tract infections are among the most common bacterial infections encountered by primary care physicians [8]. In general pediatric practice in USA, $20 \%$ of all office visits are for febrile illnesses, and urinary tract infection accounts for approximately $4-8 \%$ of these occurrences [9]. Although the case description given in the questionnaire was typical of the symptoms of acute pyelonephritis and the years of experience were comparable for physicians in the two groups, there was a great discrepancy in the attitude of general practitioners from hospital pediatricians in terms of diagnosis, investigations and treat- ment of this problem. In contrast to the majority of hospital pediatricians, most general practitioners preferred to treat acute pyelonephritis with oral antibiotics on an outpatient basis. Although recent studies had proved the efficacy and safety of treating children with febrile urinary tract infections with oral antibiotics as outpatients [10], nevertheless, this should be conditioned by a stable clinical status of the child, proper antibiotic choice and guarantee of family compliance [9]. Unfortunately, this did not apply to the general practitioners' choice given the fact that the child was ill and the antibiotics chosen did not provide enough coverage. Hospital admission is indicated in any child with acute pyelonephritis who is systemically ill [11]. These patients need careful monitoring and repeated clinical examination. The parenteral route of administering antibiotics has been, for a long time, recommended in acute pyelonephritis because it ensures optimal antibiotics blood levels in these patients [12]. A small number of both groups, $13 \%$ of general practitioners and $9 \%$ of hospital pediatricians, preferred delaying treatment till the urine culture result was obtained. This would normally take at least $48 \mathrm{~h}$ in hospital, and a longer period in prima- 
ry health care centers where laboratory facilities are not always available. Although urinalysis cannot substitute for a urine culture to document the presence of urinary tract infection, microscopic examination with gram stain of a fresh uncentrifuged clean sample can give reliable and rapid results to help in selecting individuals for prompt initiation of treatment while awaiting the results of urine cultures. Clinical and experimental data support the concept that delay in instituting appropriate treatment in acute pyelonephritis increases the risk of renal damage [12]. The majority of general practitioners and hospital pediatricians agreed on a minimum of 1-week course of treatment, which appeared to be an acceptable duration to eradicate infection. Most studies had supported the fact that long treatment duration (7-10 days) had a better outcome than short-duration treatment, i.e., up to 3 days [12]. Third-generation cephalosporins are the most widely used antibiotics for any serious infection in the hospital, which explains the preference of such antibiotics to treat acute pyelonephritis by hospital pediatricians. Due to the limited variety of oral antibiotics in primary health care centers, it was not surprising that most general practitioners preferred trimethoprim-sulfamethoxazole or penicillin. These antibiotics may be helpful in children with cystitis but will not give a full coverage for a child with acute pyelonephritis. Only $25 \%$ of general practitioners and $58 \%$ of hospital pediatricians thought radiological imaging was needed after treating the acute infection. These figures indicate the lack of awareness of the important role of imaging studies in the evaluation of a child with acute pyelonephritis. It is recommended that all children diagnosed to have urinary tract infection should have some form of imaging after the first proven infection [10-13]. These include a good quality ultrasound of the kidney and bladder and a mictu- rating cystourethrogram. ${ }^{99 \mathrm{~m}} \mathrm{Tc}$-dimercaptosuccinic acid (DMSA) scintigraphy can be done 3-6 months postinfection to rule out renal scarring. Both groups were aware of the importance of follow-up for children with acute pyelonephritis, particularly those with underlying renal anomalies. The need for checking their urine during any febrile illness as well as every 2-3 months on a regular basis is important in detecting recurrence of these infections [11]. In general, these results show that general practitioners in all primary health care centers tend to underdiagnose as well as undertreat acute pyelonephritis in children. This is most likely due to the lack of awareness of symptoms which differentiate acute pyelonephritis from cystitis. Although this is disappointing, it is not surprising. Most general practitioners, at least in Kuwait, have limited experience in pediatric diseases and the majority of them do not deal with the longterm sequelae of urinary infection, such as renal scarring and hypertension. This is well known to be a universal problem in both developing as well as developed countries. Studies in different European countries such as United Kingdom, France and Belgium had confirmed the same results [4-6, 14]. Jones [4] in 1996 showed that many doctors involved in the primary care of sick children in Wales were unaware of the symptoms associated with urinary tract infections in early childhood.

In another study done by the South Bedfordshire Practitioners' Group [14] in the UK on children with renal scarring, it was found that half of them had received suboptimal medical care by general practitioners due to failure to investigate a possible urinary tract infection. Proper radiological investigations are essential in young children presenting with acute pyelonephritis to rule out underlying abnormalities of the genitourinary tract [15-17]. Vesicoureteric reflux is encountered 
in approximately $20 \%$ of the girls with a first urinary tract infection and in $45 \%$ of those with recurrent infection [8]. Moreover, diagnosis of acute pyelonephritis in small children on several occasions cannot be made or confirmed in many cases on the basis of either clinical signs and symptoms or laboratory parameters alone $[7,17]$

\section{Conclusion}

This survey alerts to the need of a unified policy in the management of childhood urinary tract infections. This could only be attained by a combined effort to promote medi- cal education among physicians working at the primary health centers and to ensure better training opportunities for them through more frequent contact with hospital services. The provision of general practitioners with the necessary facilities for immediate urinalysis, access to a broad spectrum of antibiotics and clear practical guidelines for treating such children will certainly cut down health expenses and reduce hospital admissions. Subsequent necessary investigations, such as ultrasound, micturition cystourethrogram and DMSA scans as well as follow-up of these children can be arranged in cooperation with hospital pediatricians as needed.

\section{References}

1 Ditchfield M, De Campo JF, Cook DJ, Nolan T, Powell H, Sloane R, Grimwood K, Cahill S: Vesicoureteral reflux: An accurate predictor of acute pyelonephritis in childhood urinary tract infection. Radiology 1994:190:413-415.

2 Rushton HG: The evaluation of acute pyelonephritis and renal scarring with $99 \mathrm{~m}$ Tc-dimercaptosuccinic and renal scintigraphy: Evolving concepts and future directions. Pediatr Nephrol 1997;11:108-120.

3 Nuutinen M, Uhari M, Murphy M, Hey K: Clinical guidelines and hospital discharges of children with acute urinary tract infections. Pediatr Nephrol 1999;13:45-49.

4 Jones KV: Vesico-ureteric reflux: A medical perspective on management. Pediatr Nephrol 1996;10: 795-797.

5 Levtchenko E, Levy J, Ham H, Piepsz A: National audit: Diagnosis and treatment of acute pyelonephritis. Pediatr Nephrol 1999;13:C49.

6 Cornu C, Cochat P, Collet JP, Delair S, Haugh MC, Rolland C: Survey of the attitudes to management of acute pyelonephritis in children. Pediatr Nephrol 1994;8:275-277.
7 Andrich MP, Majd M: Diagnostic imaging in the evaluations of the first urinary tract infection in infants and young children. Pediatrics 1992;90:436-440.

8 Ahmed SM, Swedlund SK: Evaluation and treatment of urinary tract infections in children. Am Fam Physician 1998;57:1573-1580.

9 Shapiro E, Elder JS: The office management of recurrent urinary tract infection and vesicoureteral reflux in children. Urol Clin North Am 1998;25:725-734.

10 Hoberman A, Wald ER, Hickey RW, Baskin M, Charron M, Majd M, Kearney DH, Reynolds E, Ruley J, Janosky JE: Oral versus initial intravenous therapy for urinary tract infections in young febrile children. Pediatrics 1999;104:79-85.

11 The Independent Review for Doctors and Pharmacists from Consumer's Association: The management of urinary tract infection in children. Drug Ther Bull 1997;35:6569.

12 American Academy of Pediatrics, Committee on Quality Improvement, Subcommittee on Urinary Tract Infections: Practice parameters: The diagnosis, treatment and evaluation of the initial urinary tract infection in febrile infants and young children. Pediatrics 1999; 103:843-852.

13 Royal College of Physicians Research Unit Working Group: Guidelines for the management of acute urinary tract infections in childhood. J R Coll Physicians Lond 1991;25:36-42.

14 South Bedfordshire Practitioners' Group: Development of renal scars in children: Missed opportunities in management. BMJ 1990;301:10821084.

15 Montgomery DF, Parks DK, Yetman RJ: Managing urinary tract infections in children. J Pediatr Health Care 1998;12:268-270.

16 The Swedish Pediatric Nephrology Association: Urinary tract infections in children below two years of age: A quality assurance project in Sweden. Acta Paediatr 1999;88: 270-274.

17 Vernon S, Foo CK, Coulthard MG: How general practitioners manage children wit urinary tract infection: An audit in the former Northern Region. Br J Gen Pract 1997;47:297300 . 